\title{
Health Risk Effect of Heavy Metals from Pesticides in Vegetables and Soils: A Review
}

\author{
Jibrin, $\mathbf{M}^{1^{*}}$, Abdulhameed . $^{2}$, Nayaya, A.J ${ }^{2}$ \& Ezra, A. $\mathbf{G}^{2}$ \\ ${ }^{1}$ Department of Biological Sciences \\ Aminu Saleh College Of Education \\ PMB 044, Azare Bauchi State \\ ${ }^{2}$ Department of Applied Ecology \\ Abubakar Tafawa Balewa University, \\ P. M. B. 0248, \\ Bauchi Bauchi State, Nigeria
}

Email: Mayan.Adamu@gmail.com

\begin{abstract}
Vegetables are vital to the human diet, and in particular provide the well-known nutrients to maintain normal physiological functions. The prolonged application of large amount of pesticides has resulted in heavy metal accumulation in vegetable farms. Exposure to heavy metals by the consumption of contaminated vegetables and its toxicity is a serious concern. This article reviews the effect of pesticides, heavy metals, heavy metals in vegetables, heavy metals in soil and transfer of heavy metals from soil to plants. However, a limited number of studies were found in the data base that examined the reduction of nutrients in vegetables due to heavy metal contamination. The heavy metals were found in leafy and fruit vegetables in different regions of the world and levels were above permissible limits in most of the vegetables. Specific study to human toxicity due to the contamination of heavy metals may be conducted. Furthermore, strategy and policy should be devised to control the heavy metals in vegetables, and those vegetables that are hyper-accumulators of heavy metals should be identified for awareness purposes.
\end{abstract}

Keywords: Vegetables, Heavy metals, Permissible limit, Toxicity, Contamination and Hyper-accumulators

\section{INTRODUCTION}

Polluting vast areas worldwide, heavy metals are highly reactive and toxic at certain concentrations, posing severe risks to human and ecosystem health (Huang et al., 2020). While many heavy metals are naturally present in the earth's crust and atmosphere, humans may promote heavy metal pollution through activities such as mining, smelting, transportation, military operations and industrial manufacturing, as well as applying metalcontaining pesticides and fertilizer in commercial agriculture (Xiang et al., 2020). These activities release metals into the environment through waste disposal, runoff and application of heavy metal - laden chemical products, which then may enter terrestrial system via aerial deposition, surface waters or soil (Ishaq et al., 2020). Unlike organic pollutant counterparts, heavy metals cannot be degraded or destroyed. As a result, heavy metals persist in the 
environment for years, well after point sources of pollution have been removed (Magaji et al., 2020). The Agency for Toxic Substances and Disease Registry (ATSDR, 2011) has classified heavy metal as metalloids such as Asenic, Leaq and Cadmium found in the environment as 1, 2 and 7 on the basis of toxicity. These elements have no beneficial role in plants, animals and humans and have no nutritional function, as they are highly toxic (Manzoor et al., 2018).

Pesticides are chemicals used for pest control and are probably the most widely distributed contaminants in the environment. Ideally, a pesticide must be lethal to the target pests, but not to non-target species, including humans. Unfortunately, this is not the case. Inadequate management of pesticides constitutes potential occupational hazards and environmental risks for ecosystems (Gomez et al., 2012). Besides, pesticides residues retained in crops can directly influence public health via food consumption. The World Health Organization has reported a million cases of pesticide poisoning worldwide and also provided evidence that pesticides were responsible for many diseases affecting human health (WHO, 1999). In fact, pesticide pollution have been implicated in the rise of cancer incidence, probably due to consumption of vegetables or water that are contaminated with pesticides (Miret et al., 2015).

The aim of this paper was to summarize the literature on the effect of heavy metals due to pesticides on vegetables and soils as well as their harmful effect to living organism.

\section{PESTICIDES AND ITS EFFECTS}

According to estimates by the World Health Organization (WHO) each year between 500,000 and 1 million people are poisoned by pesticides and between 5,000 and 20,000 die. At least half of the intoxicated and $75 \%$ of those who die are agricultural workers, the rest is due to poisoning by eating contaminated food. In total, mortality between the two groups reached 220,000 deaths per year (WHO 1999, Yuguda et al., 2015). Although pesticides have been developed to produce toxic effects in the fighting of pests, these effects may also have the potential to affect other living organisms, though the possibility of this occurring will only be if exposure reaches sufficient levels to produce the toxic effect. Therefore, besides knowing the physical, chemical and toxic nature of pesticides, knowledge on the estimated potential exposures of humans and other organisms to these pesticides, depending on the type of toxic effect they exert must be known, because these chemicals may affect the growth and survival of reproductive factors, and in the case of acute toxicity may cause death of exposed organisms (Adams et al., 2021). Pesticides have also been associated with long-term carcinogenicity, mutagenicity, reproductive and hormonal effects, amongst others. Agrochemicals able to induce changes in the genetic material of somatic and germinal tissue are considered mutagenic, contributing to the appearance of congenital malformations and cancer etiology (Upadhayay et al., 2012). Epidemiological studies have associated with the cancer, gastric, skin, kidney, liver, prostate, testis in individuals exposed; besides sarcomas, leukemia, non- Hodgkin lymphoma, myeloma and others (Martine, 2016).

\section{HARMFUL EFFECTS OF SOME HEAVY METALS}

\section{Arsenic}

Arsenic (As) is a toxic element and remains a significant human health concern as As and its compounds (inorganic) are carcinogenic to humans and are classified as Group 1. Organic As compounds such as mono- and dimethylarsinic acids are possibly carcinogenic to humans and are classified as Group 2B by International Agency for Research 
on Cancer (IARC, 2012). Arsenic exposure causes an elevated risk for developing a number of cancers, most notably skin cancer, and cancers of the liver, lung, bladder, kidney and colon (Banerjee et al., 2021). Several studies carried out to determine the linear relationship between As contents of vegetation and its concentration in soils of both total and soluble species suggest that plants take up As passively with the water flow. It was also observed that the use of As-rich irrigation water and soil affected plant height, crop yield, and development of root growth (Wen et al., 2021).

\section{Cadmium}

Cadmium $(\mathrm{Cd})$ is an element of great concern from the toxic point of view, and its exposure can cause both chronic and acute health effects in living organisms. $\mathrm{Cd}$ occurs naturally in the earth's crust and in ocean water (IARC, 2012). The terrestrial abundance of $\mathrm{Cd}$ on average is $0.1-0.2 \mathrm{mg} / \mathrm{kg}$, whereas, in ocean waters, it ranges from $<5$ to $110 \mathrm{ng} / \mathrm{L}$ on average (IARC, 2012). Cd and its compounds are carcinogenic to humans and are classified as Group 1 by International Agency for Research on Cancer, as $\mathrm{Cd}$ and its compounds have been reported to cause cancer of the lung, and positively associated with cancers of the kidney and prostate. $\mathrm{Cd}$ intoxication can also lead to pulmonary damages, kidney damage, skeletal damage, and itai-ita .(Manzoor et al., 2018). In drinking water the tolerable concentration set by WHO is $0.003 \mathrm{mg} / \mathrm{L}$ for Cd (IARC, 2012).

\section{Lead}

Lead $(\mathrm{Pb})$ exposure in children and adults can cause a wide spectrum of health problems, ranging from small effects on metabolism and intelligence to convulsions, coma, renal failure, and death (Marshal et al., 2020) As per International Agency for Research on Cancer evaluation, inorganic $\mathrm{Pb}$ compounds are found at low concentrations in the earth's crust predominantly as lead sulfide (galena), but the widespread occurrence of lead in the environment is largely the result of anthropogenic activity. $\mathrm{Pb}$ enters the environment at any stage from its mining to its final use, and it contaminates crops, soil, water, food, air, and dust (IARC, 2012). In vegetable, the tolerable concentration set by WHO is $0.3 \mathrm{mg} / \mathrm{L}$ for $\mathrm{Pb}$ (IARC, 2012).

\section{Nickel}

Nickel (Ni) is widely distributed in nature and is found in animals, plants, and soil; the concentration of $\mathrm{Ni}$ in soil is approximately in the range of 4-80 ppm (IARC, 2012, ATSDR 2011). Large amount of $\mathrm{Ni}$ is released in the atmosphere due to natural as well as anthropogenic activities including fossil fuel consumption, industrial production (mining, smelting, and refiing), use, and disposal of nickel compounds and alloys, as well as inceneration of waste (ATSDR 2011). Human exposure to Ni results from Ni contaminated food ingestion, water, inhalation, and percutaneous absorption (IARC, 2012, ATSDR 2011). According to International Agency for Research on Cancer evaluation, Ni compounds are carcinogenic to humans and are classified as Group 1. Mixtures of Ni metal and compounds causes cancer of the lung, nasal cavity and paranasal sinuses (ATSDR 2011). In vegetable, the tolerable concentration set by WHO is $0.003 \mathrm{mg} / \mathrm{L}$ for Ni (IARC, 2012).

\section{Copper}

Copper is an essential element and is always present in food and in animal liver, and hence, serve as the major contributors to dietary exposure (Shekh et al., 2021). Cu acts as a reductant in the enzymes superoxide dismutase, cytochrome oxidase, lysyl oxidase, dopamine hydroxylase, and several other oxidases that reduce molecular oxygen. It is transported in the organism by the protein ceruloplasmin (Shekh et al., 2021). The recommended dietary 
allowance (RDA) for adults is $0.9 \mathrm{mg} /$ day. In vegetable, the tolerable concentration set by $\mathrm{WHO}$ is $40.00 \mathrm{mg} / \mathrm{L}$ for $\mathrm{Cu}$ (IARC, 2012).

\section{Chromium}

Chromium is an important element especially in metallurgical/steel or pigment industry. Both of its oxidation forms $(+3$ and +6$)$ in the chemical are used primarily in pigments, metal finishing, and wood preservatives (Alipour et al., 2021). The main sources of $\mathrm{Cr}$ pollution have been reported to be from dyestuff and leather tanning particularly when wastes are discharged directly into waste streams. Cr potentiates the action of insulin and may improve glucose tolerance. Its $+3(\mathrm{Cr} 3+$, or $\mathrm{Cr}$ (III)) form which is the most stable oxidation state is found in food while its compound occur naturally (Stern 2010). In vegetable, the tolerable concentration set by WHO is $2.3 \mathrm{mg} / \mathrm{L}$ for $\mathrm{Cr}$ (IARC, 2012).

\section{Zinc}

Zinc is an essential micronutrient that catalyzes enzyme activity, contribute to protein structure, and regulate gene expression (DRI 2001). Although the consequences of Zn deficiency have been recognized for many years, it is said to be toxic when exposures exceed physiological needs (kabata-pendias, 2011). The adverse effects associated with chronic intake of supplemental $\mathrm{Zn}$ include acute gastrointestinal effects, headaches, impaired immune function, changes in lipoprotein and cholesterol levels, reduced copper status, and zinc-iron interactions ( $\mathrm{Li}$ et al 2020). In vegetable, the tolerable concentration set by WHO is $60.00 \mathrm{mg} / \mathrm{L}$ for Zn (IARC, 2012).

\section{HEAVY METALS IN VEGETABLES}

Vegetables are an important source of human diets, and their contamination can cause serious health problems (Lim et al. 2008; Zhang et al.., 2020). Leafy vegetables like lettuce are considered to be potential hyper accumulators of heavy metals (Ramos et al. 2012; Manzoor et al., 2018). One of the properties of green leafy vegetable is the accumulation of heavy metals in their tissues without exhibiting any toxicity symptoms. (Manzoor et al., 2018). Monteiro et al. (2017) reported that with increasing exposure duration, the concentrations of heavy metals in lettuce roots and shoots increased. Heavy metals can cause changes in physiology and growth of tomato at variable concentrations resulting in chlorosis and necrotic symptoms on leaves (López-Millán et al. 2019). Garate et al. (2020) described that lettuce as having a higher capacity to accumulate heavy metals in different tissues. Heavy metal uptake is also affected by different vegetable species and within the same species by different cultivars (Manzoor et al., 2018).

Concentration of heavy metals vary in different parts of the same plant. Xu et al. (2019) reported the heavy metal accumulation in the order of leaf greater than root, root has equal concentration with stem and stem has higher concentration than tuber. However, other scientists reported that the root concentrations are higher than that in the shoot (Bawa et al., 2020). In fruit plants like tomato, the translocation rate of heavy metals to the fruit is rather low, hence characterized as low-rate translocation fruit vegetable (Angelova et al. 2019). Accumulation and distribution of heavy metals like $\mathrm{Cd}$ have been found in different parts of tomato (Bawa et al., 2020). Vegetables are vulnerable to heavy metals at high concentrations, and large-scale irrigation with wastewater and application of pesticides and fertilizers for commercial production increase the risk of heavy metal contamination (Agelova et al. 2020). 
Heavy metals have significantly negative effects on plant growth (López-Millán et al. 2019); other toxic effects may include root browning, alteration of mineral concentrations, and changes in photosynthesis (López-Millán et al. 2019).

\section{HEAVY METALS IN SOIL}

Soil contamination with heavy metals is a serious global environmental problem posing risks to human, animals, microbes and plants in addition to contaminating surfaces and ground water (Yang et al., 2010) Heavy metal and other pollutants enter into the soil ecosystem through natural processes and anthropogenic activities (Bu et al., 2020) like solid waste disposal, waste water irrigation, sludge application, automobile exhaust, mining and smelting process, urbanization, agricultural activities and industrialization also contribute heavy metals into the soil environment (Yang 2010, Bu et al., 2020). Similarly, the physiochemical characteristics of soil have substantial effects on heavy metal concentration and it availability to plant.

Heavy metal concentration in the soil is greatly affected by the soil's organic content (Khan et al. 2019). Soils with high organic waste concentrations are generally confined to heavy metal concentrations of less than $1000 \mathrm{mg} / \mathrm{kg}$ soil, while industrial waste-contaminated soil contains more than 10,000 mg/ $\mathrm{kg}$ soil (Bader et al. 1999). Increasing concentrations and variation in distribution of heavy metal in metal-amended soil generally augment the heavy metal concentrations in plants (Castro et al. 2019). Soil is the main source of food contamination with heavy metals because soil is used as an important tool for waste management and waste dumping (Salem et al., 2020).

The prime route of heavy metal intake into the human body is through soil-crop system in the area of agriculture (Liu et al. 2017), in urban environment through ingestion, absorption through skin, and inhalation of dust particles (Ahmed et al., 2016), whereas the primary source of pollution in urban soil is via anthropogenic route which includes vehicular emission, power plant, tire wear particles, auto repair shops, car wash centers, brake lining, coal combustion, chemical plants, weathering of building, atmospheric deposition, and house hold solid waste (Liu et al., 2017; Madrid et al., 2020)

\section{TRANSFER OF HEAVY METALS FROM SOIL TO PLANTS}

Metals may enter soils through several pathways, including runoff from roads and industrial sites, metallopesticides, phosphate fertilizers, application of treated and untreated sewer sludge, and atmospheric deposition of metal containing particles (Manzoor et al., 2018). However, the risk of metals entering a food chain depends on the mobility of the metal and its availability in the soil. In the soil, metal cations are bound to negatively charged particles such as clay and organic matter (When metals detach from these soil particles and enter the soil solution, they become bioavailable with potential to accumulate in plants and other soil-dwelling organisms Rajakaruna and Boyd 2018). Several studies reveal the effects of various physical, chemical, and biological processes on the bioavailability of metals in soils (Peralta-Videa et al., 2019; Maestri et al., 2020). In particular, Peralta-Videa et al. (2019) described the mobility of $\mathrm{Cd}, \mathrm{Cr}, \mathrm{Hg}$, As, and $\mathrm{Pb}$ in soils and their potential for uptake by plants, a process that is also mediated by rhizospheric microbial activity (Wenzel 2019). At low $\mathrm{pH}$, certain metals, such as $\mathrm{Cd}, \mathrm{Cu}, \mathrm{Hg}$, and $\mathrm{Pb}$, become more available for plant uptake (Huang et al., 2020). Soil bacteria, including those in the rhizosphere may also release compounds such as antibiotics, antifungals, organic acids, hormones, and metal chelators into the soil, which may increase or decrease metal bioavailability to other organisms (Xiang et al., 2020; Wenzel 2019). Many studies stress the importance of bioavailability assays of metals when assessing the risk of metal accumulation and transfer in terrestrial food webs (Gupta et al., 2020), but the effectiveness of these 
bioavailability assay methods are debated (Menzies et al., 2017). Although some heavy metals, such as $\mathrm{Ni}, \mathrm{Cu}, \mathrm{Fe}, \mathrm{Mn}$, and $\mathrm{Zn}$, are important to particular biological processes in plants (Xiang et al., 2014), when they occur in excess, these metals, can disrupt critical physiological processes resulting in toxicity. Thus, most plants exclude excess bioavailable metals at their roots by binding them to organic acids or ligands, or storing them within vacuoles where they cannot interfere with important physiological processes (Rajakaruna, 2018). However, not all plants exclude heavy metals: certain plants can tolerate and accumulate bioavailable metals into above-ground tissues (Huang et al., 2020.

\section{CONCLUSION}

Vegetables are the major dietary source of vitamins and fiber being consumed all over the world. They play a significant role in nutritional contribution to the consumers. They are the rich sources of essential nutrients, however, they are strong accumulators of heavy metals and pose great risk to human health. The health effects of heavy metals are direct as well as indirect. Direct impacts involve direct consumption through vegetables, ingestion and dermal contacts this may cause various cancer such as cancer of the skin, colon lungs etc or leads to damage of organs, while indirect impacts includes reduction in nutritional components in contaminated food crops and can lead to lack of some important nutrient in plants. The presence of these heavy metals in vegetables causes so many health problems comprising of different carcinogenic and non-carcinogenic diseases resulting from the transfer of heavy metals from soil to the plant, and then to humans through the food chain. Specific study on the toxic effect of consumption of food crops contaminated by heavy metals in human may be conducted. Furthermore, strategy and policy should be devised to control the heavy metals in vegetables while those vegetables that are hyper-accumulators of heavy metals should be identified for awareness purposes.

\section{REFERENCES}

Adams, B.D., Hirata, H and Hyate S.A (2021). Concentration distribution and assessment of heavy metals in surface sediments in the some islands. Soil Sci. Plant Nutr. 41, 481 - 496.

Ahmed, M., Azrina, A., Mohd Yunus, A.S., Mohd Zakiuddin, S., Mohd Izuan Effendi. (2016). Heavy metals (mercury, arsenic, cadmium,lead) in selected marine fish and shellfish along the Straits of Malacca. Int. Food Res. J. 19, 135e140.

Alipour M., Asadi H., Chen C. and Rashti M.R. (2021). Bioavailability and ecotoxicity of heavy metals in chars produced from municipal sewage sludge decreased during pyrolysis and hydrothermal carbonization. Ecolgical engineering. 162 (106-173)

Angelova VR, Babrikov TD, Ivanov KI (2019) Bioaccumulation and distribution of lead, zinc, and cadmium in crops of Solanaceae family. Commun Soil Sci Plant Anal 40:2248-2263

ATSDR, (2011) Toxicological Profie for Nickel, Agency for Toxic Substances and Disease Registry, US Public Health Service.

Benerjee, R. S. (2021). Ecology of metal hyperaccumulation. New Phytologist, 162, 563-567.

Bader JL, Gonzalez G, Goodell PC (1999) Chromium-resistant bacterial populations from a site heavily contaminated with hexavalent chromium. Water Air Soil Pollut 109:263276

Bawa U, Abdulhameed A; Nayaya A J; Ezra A G; Jibrin M (2020). Bioaccumulation factor of heavy metals in some crops grown in plateau state, Nigeria. 
Bu X, Feng X, Yang Y, Qiu G, Li G, Li F, Liu T, Fu Z, Jin Z (2020) Environmental contamination of heavy metals from zinc smelting areas in Hezhang County, western Guizhou, China. Environ Int 32:883-890

Castro E, Villares R, Puente X, Carba Ueira A (2019) Influence of watershed lithology on heavy-metal levels in estuarine sediments and organisms in Galicia (north-west Spain). Mar Pollut Bull 30:604- 608

Garate A, Ramos I, Manzanares M, Lucena JJ (202-) Cadmium uptake and distribution in three cultivars of Lactuca sp. Bull Environ Contam Toxicol 50:709-716

Gomez C, Boluda R, Ramos J (2012) Determination and evaluation of cadmium lead and nickel in greenhouse soils of Almeria (Spain).

Chemosphere 55:1027-1034

Gupta R., Zhu Y. and Zhao Y. (2020). Effect of zinc, cadmium and mercury on solid waste incinerated bottom ash.. Environ Sci 14(1): 721-734

Huang HM, Zheng CR, Tu C, Zhu YG (2020) Heavy metal pollution in soils in China: status and countermeasures. Ambio 28:130-134

IARC. (2012) A Review of Human Carcinogens: Metals, Arsenic, Fibres and Dusts, vol. 100C, International Agency for Research Cancer: Monographs on the Evaluation of Carcinogenic Risks to Humans

Ishaq, M., Mohammad, S., Nabavi, B., Parsa, Y., 2013. Bioaccumulation of trace Nmercury in trophic levels of benthic, benthopelagic, pelagic fish species, and seaNbirds from Arvand river, Iran. Biol. Trace Elem. Res. 156, 175e180.

Kabata-Pendias., A. (2011). Trace Elements in Soils and Plants, CRC Press, New York, NY, USA, 2011

Khan S, Rehman S, Khan AZ, Khan MA, Shah MT (2019) Soil and vegetables enrichment with heavy metals from geological sources in Gilgit, northern Pakistan. Ecotoxicol Environ Saf 73:1820-1827

Li Q, Cai S, Mo C, Chu B, Peng L, Yang F (2020) Toxic effects of heavy metals and their accumulation in vegetables grown in a saline soil. Ecotoxicol Environ Saf 73:84-88

Lim H-S, Lee J-S, Chon H-T, Sager M (2008) Heavy metal contamination and health risk assessment in the vicinity of the abandoned Songcheon Au-Ag mine in Korea. J Geochem Explor 96:223-230

Liu H, Probst A, Liao B (2017) Metal contamination of soils and crops affected by the Chenzhou lead/zinc mine spill (Hunan, China). Sci Total Environ 339:153-166

López-Millán A-F, Sagardoy R, Solanas M, Abadía A, Abadía J (2019) Cadmium toxicity in tomato (Lycopersicon esculentum) plants grown in hydroponics. Environ Exp Bot 65:376-385

Madrid D, Cornu S, Bourennane H, Baize D, Ratié C, King D (2020) Effect of agricultural practices on trace-element distribution in soil. Commun Soil Sci Plant Anal 38:473491

Magaji, I.R., Hafeez, L., Abdulhamid, A., Benthal, G., Bello, A.B.A., et al., (2020). Climate change and food security: health impacts in developed countries. Environ.Health Perspect. 120, 1520e1526

Martilet MK, Van Laerhoven CJ (2016) Differential effects of cadmium on lettuce varieties. Environ Pollut 4:7-15

Miret, E.J., Leyval, C., (2015). Uptake of 109Cd by roots and hypae of a Glomus mosseae/Trifolium subterraneum mycorhiza from soil amended with high and low concentration of cadmium. New Phytol. 135,353 \pm 360 .

Manzoor J., Sharma M. and Wanu A.K. (2018). Heavy metals in vegetables and their impact on the nutrient quality of vegetables: A review. Journal of plant nutrition. DOI: 10.1080/01904167.2018.1462382 
Marshal H., (2020). Role of root growth, arbuscular mycorrhiza and root exudates for the efficiency in nutrient acquisition. Field Crops Res. 56, $203 \pm 207$.

Martine S. M., Dodo J. D and Nelsa R. A. (2016). Enviromental impact of pesticides usage of farmlands in Nigeria. International journal of innovative reaerch and development. 5: $311-317$

Menzies A, Sacchi E, Mallen L (2017)Multivariate statistical and GIS based approach to identify heavy metal sources in soils. Environ Pollut 114:313-324

Monteiro M, Santos C, Mann RM, Soares AMVM, Lopes T (2017) Evaluation of cadmium genotoxicity in Lactuca sativa L. using nuclear microsatellites. Environ Exp Bot 60:421-427

Maestri, R.K., P eger, F.L., Norland, M.R., (2020). Field responses to added organic matter, arbuscular mycorrhizal fungi, and fertilizer in reclamation of torbonite iron ore tailing. Plant Soil, 179, 89 \pm 97.

Rajakaruna N. (2018). Distribution of Heavy metals in tannery e.uent polluted soils of Tamil Nadu, India. Bull. Environ. Contamin. Toxicol. 60, 142 \pm 150 .

Ramos I, Esteban E, Lucena JJ, Gárate A (2012) Cadmium uptake and sub cellular distribution in plants of Lactuca sp. Cd-Mn interaction. Plant Sci 162:761-767

Saleem U., Saba S., Hamid M.S., Rehman K., Fiayyaz F. and Ahmad T. (2020). Assessment of heavy metals by ICP-OES and their impact on insulin stimulating hormone and carbohydrate metabolizing enzymes. Clinical and Experimental Pharmacology. 47(10): 1682-1691.

Shekh, K.G., Banks, M.K., Hetrick, B.A., Schwab, A.P., (2021). Effects of mycorrhizae and fertilizer amendments on zinc tolerance of plants. Environ. Pollut. 88, 307 \pm 314 .

Stern, B. R. (2010) "Essentiality and toxicity in copper health risk assessment: overview, and regulatory considerations," Journal of Toxicology and Environmental Health A, vol. 73, no.2-3, pp. 114-127, 2010.

Wenzel, (2019). Root colonization of maize by a Cd-sensitive and a Cd-tolerant Glomus mosseae and cadmium uptake in sand culture. Plant Soil 175, 233 \pm 238 .

Wen BG, Yang LS (2021) A review of heavy metal contaminations in urban soils, urban road dusts and agricultural soils from China. Microchem J 94:99-107

WHO (1995). Lead environmental health criteria. Geneva: World Health Organization, 1995:165.

Xiang Z, Tao S, Pan B, Fan W, He XC, Zuo Q, Wu SP, Li BG, Cao J, Liu WX, Xu FL,Wang XJ, ShenWR,Wong PK (2014) Contamination of rivers in Tianjin, China by polycyclic aromatic hydrocarbons. Environ Pollut 134:97-111

Xu D, Chen Z, Sun K, Yan D, Kang M, Zhao Y (2019) Effect of cadmium on the physiological parameters and the subcellular cadmium localization in the potato (Solanum tuberosum L.). Ecotoxicol Environ Saf 97:147-153

Ypadhayaya, J.L., Zhang, C.X., Wang, Y.X., Liao, X.P., Yao, L.L., et al., (2012). Pollution characteristics and distribution of polycyclic aromatic hydrocarbons and organochlorine pesticides in groundwater at Xiaodian Sewage Irrigation Area, Taiyuan City. Huan. Jing. Ke. Xue 36, 172e178

Yang C, Liu C, Wang Y, Liu X, Li F, Zhang G, Li X (2010) Heavy metal contamination in soils and vegetables near an e-waste processing site, south China. J Hazard Mater 186:481490

Yuguda, A. U., Abubakar Z. A., Jibo A. U., AbdulHameed, A. \& Nayaya, A. J. (2015). Assessment of Toxicity of Some Agricultural Pesticides on Earthworm (Lumbricus Terrestris). American-Eurasian Journal of Sustainable Agriculture. 9(4): 49-59 
Zang, C., Col, A. Soran, B. S. Sayli, and S." Ozturk.(2020) "Arsenic-" related Bowen's disease, palmar keratosis, and skin cancer," Environmental Health Perspectives, vol. 107, no. 8, pp. 687-689, 